Blaxter, K. L. (1964). In The Role of the Gastrointestinal Tract in Protein Metabolism p. I48 [H. N. Munro, editor]. Oxford: Blackwell Scientific Publications.

Bolton, W. (1964). In The Role of the Gastrointestinal Tract in Protein Metabolism p. II7 [H. N. Munro, editor]. Oxford: Blackwell Scientific Publications.

Crane, C. W. (1964). In The Rale of the Gastrointestinal Tract in Protein Metabolism p. 333 [H. N. Munro, editor]. Oxford: Blackwell Scientific Publications.

Freeman, T. (1964). In The Role of the Gastrointestinal Tract in Protein Metabolism p. 125 [H. N. Munro, editor]. Oxford: Blackwell Scientific Publications.

Hecker, J. F. $(1967)$. Studies on the metabolism of nitrogenous compounds in the large intestine of herbivores. PhD Thesis, University of Cambridge.

Nasset, E. S. \& Ju, J. S. (196I). Y. Nutr. 74, 46r.

Pelot, D. \& Grossman, M. I. (I962). Am. Y. Physiol. 202, 285.

Williams-Smith, H. (1965). F. Path. Bact. 89, 95.

Wilson, T. H. (1962). Intestinal Absorption Ch. 5. Philadelphia \& London: W. B. Saunders Company.

\title{
Problems in the assessment of vitamin deficiency
}

By R. H. Girdwood, University Department of Therapeutics, The Royal Infirmary, Edinburgh $\mathrm{EH}_{3}{ }_{9} \mathrm{YW}$

The modern British doctor may never wittingly have seen a patient with vitamin deficiency due to primary malnutrition and, unless he is the product of a medical school that encourages its students to spend an elective period in one of the developing countries, he may feel that talks on vitamin deficiency states are too unreal and academic to deserve his attendance. This is a measure of the state of our economy and of the successful policies of our nutritional experts. Those who have seen the pitiful figures in the cities or villages of large areas elsewhere in the world must view such matters in an entirely different light. However, the present account is concerned more with the problem in the United Kingdom, and particularly with the various factors concerned with the intake and availability of vitamins. From the practical point of view our clinicians may be faced with disorders arising from depletion of ascorbic acid, folic acid or calciferols. The existence in this country of patients with primary deficiency of other vitamins is more controversial. In the first instance, however, the subject will be considered in general terms.

\section{Vitamin intake and requirements}

It is not necessary to discuss here the precise amount of each of the vitamins that is believed to be required by the human male and female at different ages but, instead, the various factors that may affect the amount actually available to the body merits further consideration. At the same time, passing mention may be made of the major, general causes of individual variation in requirements. These matters in themselves could be the subject of a very long lecture or article, but may be compressed into a table, with a few added comments. Recently, I made use of an alphabetical list of aetiological factors of importance when discussing deficiency states in the elderly (Girdwood, 1970). At the risk of appearing to be lacking in imagination in my approach to the subject, $I$ have set out Table $I$ in a similar manner. 


\section{Table I. Some factors affecting vitamin intake and requirements}

Amount initially present and its availability for absorption after digestion

Bottling. Blanching

Cooking. Canning

Destruction in the preparation of foodstuffs in the home (e.g. peeling potatoes, cooking methods)

Exact form of the vitamin in the diet. Eating habits

Freshness of foodstuffs. Freezing methods

Gamma radiation

Heat, including temperature used in cooking

Illness altering requirements (including changes in absorption, metabolism, excretion)

Juices and their vitamin content

Kitchens of large institutions; loss of vitamins from cooking methods and delay in serving

Lack of knowledge by consumer. Most people buy foods because they like them

Microwave cooking and other newer methods

Neutrality or otherwise of water etc., used in cooking (destruction by acids or alkalis)

Old age and its special problems

Pregnancy altering requirements. Preservatives

Quality of foodstuffs initially, and variation in this and vitamin content in different areas of the country, and by seasons

Restoration artificially of vitamins after their destruction in processing

Stability of individual vitamins in cooking processes or with storage. Size and sex of the individual

Thawing methods

Ultraviolet and visible light - effect on vitamin content of milk

Variation in laboratory assessments of vitamin content

Water used in cooking; quantity and disposal

Xerophilation (air-drying; freeze-drying)

Youth - altered requirements when growing

Zymogens

\section{Availability of vitamins - general considerations}

Many of the headings in Table I are self explanatory, and they are obviously not applicable to all vitamins. Clearly, the amount initially present is important and this may vary in different parts of the country even in the same type of foodstuff; obviously there may be seasonal variation. The foodstuff may be eaten raw but in many instances it will be processed in some way, prepared for the table and eaten or drunk by the consumer. In the course of its journey from the place of origin to the mouth, many factors that lower the vitamin content may be introduced and indeed all traces of the vitamins may be removed. We must, therefore, first consider the circumstances under which this is important, bearing in mind the suggestion made above that in the United Kingdom we are primarily concerned with processes affecting the content of ascorbic acid, folic acid and calciferols.

\section{Theoretical considerations}

It is of interest, also, to consider whether this is true on theoretical grounds. Deficiency of retinol is unlikely in this country because there would have to be a deficiency of this stable factor from lack of dairy products together with a lack of carotenes in plants. Lack of thiamin should not occur since the vitamin occurs in the whole natural foods. It is true that it is lost with milling of cereals, from the throwing out of cooking water and from the use of baking powder, but features of thiamin deficiency occur not so much in famine as when the diet is incredibly poorly 
balanced. I heard much about it from men released from Japanese prison camps after they had lived for long periods on a diet of polished rice, but have never seen it since. Nicotinic acid is stable, but there may be some loss in processing, or from the throwing away of cooking water. It is widely distributed in plants and animal foodstuffs, but is only in small amounts except in meat, fish, wholemeal cereals and pulses. In addition, however, some may be synthesized in the body from tryptophan. Cobalamins are synthesized by micro-organisms and do not occur in plants, but there are sufficient stores in the human body to last about 3 years, so that although the absolutely committed vegetarian may develop vitamin $\mathrm{B}_{12}$ deficiency, this will take time. Riboflavin is found in liver, milk, eggs and green vegetables, and is labile when tested in alkaline solution. Bright sunlight causes some loss of this vitamin from milk, and it may also be wasted when cooking water is thrown away after vegetables are boiled. I certainly saw evidence of riboflavin deficiency in those released from Japanese prison camps but not since then. It is not quite clear why riboflavin deficiency is not more widespread. We can dismiss vitamin $\mathrm{K}$, tocopherols, pyridoxine, pantothenic acid and biotin since deficiency of these is not of practical importance in man (with the possible exception of haemorrhagic disease of the newborn from lack of vitamin $\mathrm{K}$ ), and so we find that we are back to ascorbic acid, folic acid and calciferols.

\section{Vitamins $C, D$ and folic acid}

Can we eliminate any of these on theoretical grounds? It might be argued that calciferol is not normally a vitamin, since it is synthesized in the skin. It is in the growing child, the elderly, the chronic invalid and perhaps in pregnant women that we must look for vitamin D deficiency. The quantity in milk is small and this may also be so with butter hence, in some instances, vitaminized margarine is what prevents osteomalacia or rickets. When we come to ascorbic acid, it has been suggested that we are faced with a congenital error of metabolism affecting all mankind. We share with the guinea-pig an inability to synthesize this simple reducing agent, which we obtain from fruits, green vegetables, root vegetables and potatoes. The Eskimo would be in trouble were it not for the fact that it occurs in liver and to a lesser extent in animal tissues. Cooking and processing losses may be considerable. Folic acid is more widely distributed in foodstuffs, but again much of it may be lost in cooking.

\section{Regional variation in intake}

Obviously, therefore, the type of diet together with the amount of sunlight in the United Kingdom are important in our consideration of possible vitamin deficiency states. We are concerned with the eating habits of the population, the influence on this of food manufacturers, the intake in various areas particularly of vegetables, fruit, potatoes, milk, margarine and butter, the amount of sunshine to which people are exposed and, in some areas, the extent to which a pigmented skin cuts down the 
synthesis of vitamin D if the diet is marginal. Our information is mainly derived from the Annual Reports of the National Food Survey Committee, which merit close study. In 1967 (Ministry of Agriculture, Fisheries and Food, I969) the amount spent on food was less per head in Scotland than elsewhere in Great Britain. The intake of potatoes was that of the national average, but for other sources of vitamin $\mathrm{C}$, the percentage figures below the national average were: fresh green vegetables 58 ; other vegetables 13 ; fresh fruit 22 ; other fruit 19 . The intake of margarine (a good source of vitamin D) was $27 \%$ above and of butter $23 \%$ below the national average. In the south-west of England the intake of fresh green vegetables was $53 \%$ above the average. With the passage of time, the influence of processed foods will increase in importance, and matters could become worse.

\section{Effects of processing and cooking}

When we consider food processing, packaging, reconstitution, cooking and serving, it will be seen from Table $r$ that we have to consider the influence on vitamin content of deterioration with the passage of time, of bottling, canning, blanching, heating, reheating, leaching out by cooking-water, the precise method of cooking, destruction by light, the effect of additives, the practices of the housewife, the effects of drying, freezing, thawing and of acids or alkalis. The consumer may be suffering from problems of absorption, metabolism or excretion, and may be a growing child, a pregnant woman, or somebody who is very elderly.

Valuable information about the effects of processing and cooking have been given by Bender, ( 1966 ). He says little about calciferol except that when vitamin D-enriched milk is dried nearly a third of the vitamin disappears. His catalogue of the ways in which ascorbic acid can be destroyed is a long one. Vegetables covered with water may lose $80 \%$ of their content. Bruising and wilting of fruits and vegetables allow ascorbic acid oxidase to destroy the vitamin. The method of peeling of potatoes has a significant effect on their content, and so-called fruit drinks may contain little or no ascorbic acid. However, new processes are always being developed and Glew ( 1970 ) has referred to the seasonal variation in ascorbic acid of potatoes leading to significant differences in the content of different batches of reconstituted, dehydrated potatoes particularly when this process may sometimes, but not always, lead to a loss of more than two-thirds of the vitamin $\mathrm{C}$ content. This could be serious for a community which after relying on potatoes as a source of ascorbic acid decided to use the dehydrated form. When discussing hospital kitchens he has also referred to a fall in the ascorbic acid content of frozen peas from $20.5 \mathrm{mg} / \mathrm{IoO} \mathrm{g}$ to $\mathrm{I} \cdot \mathrm{I} \mathrm{mg} / \mathrm{I} 00 \mathrm{~g}$ in the $2.5 \mathrm{~h}$ which elapsed between starting to cook them and serving them to patients. So far as folate is concerned, our problems are greater. It is possible, with difficulty, to produce a diet that is almost folate-free (Herbert, I $96_{3}$ ). Assay of the folate content before and after cooking may suggest an increase or decrease of the amount in a foodstuff, and there are many problems about the folate content of the diet. The preliminary difficulties are indicated in Table 2. 
Table 2. Difficulties in deciding about folate intake and available content in foodstuffs

Foodstuffs contain various forms of folate, largely as pteroylpolyglutamates

An enzyme (folate conjugase) hydrolyses these in the intestinal mucosa

The availability to man of various polyglutamates is uncertain

Much of the folate has to be liberated by conjugase preparations before assay. More than one may have to be added

Some foodstuffs contain conjugase inhibitors

Some conjugase preparations contain folic acid

The methods of storing, processing and cooking may alter the folate content

The content in various foodstuffs may vary in various regions

The content is usually measured microbiologically, but different test organisms may be used

These do not all measure the same forms of folate

\section{Problems of assaying folate}

The usual test organisms are Lactobacillus case $i$ and Streptococcus faecalis, and it is not yet certain how we can measure the amount of available folate in the food.

If, however, we decide upon a method, there are still many things that can cause variations in the results of any microbiological assay. This is so whether we are attempting to measure folate in foodstuffs or to show the extent to which the individual is suffering from folate depletion. In a microbiological assay method the test organism is grown in a transfer medium and inoculated into tubes containing measured amounts of the substance being studied, together with a culture medium. In other tubes the culture medium has added to it various dilutions of extracts from the foodstuffs or biological fluid that is being tested. The range of normal, say for the serum folate content, varies from laboratory to laboratory and things can go wrong at almost every stage of the test. This is illustrated in Table 3 .

Table 3. Errors that may occur in microbiological assay for folate

Culture medium

An ingredient may be omitted

An ingredient may deteriorate with keeping

An ingredient may deteriorate with light

An inhibitory substance may be present

'The $\mathrm{pH}$ may be wrong

The substance being tested for may be present in error

Another substance that substitutes for it may be present

The glassware may be contaminated

The medium may have been overheated

Tubes containing standard

Miscalculation of dilution

Inhibitor present

Standard deteriorated

Saliva in pipettes

Contaminants in glassware

Standard not set up daily

Contaminant in stoppers

Samples

Miscalculation of dilutions

Inhibitor present

Sample deteriorated

Saliva in pipettes

Contaminants in glassware or stoppers 


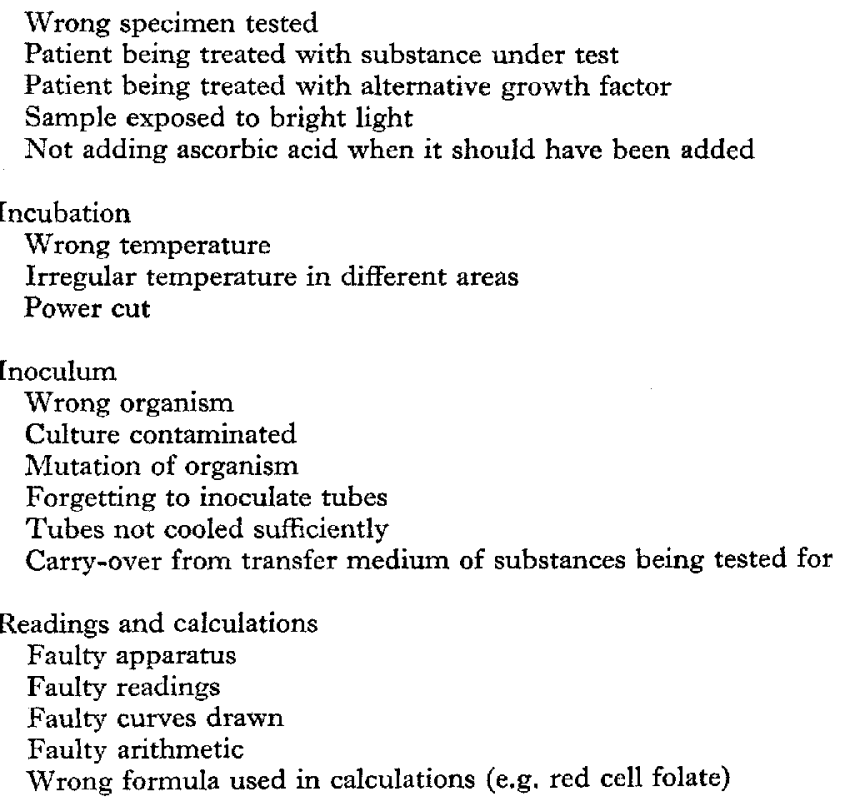

\section{Assay of other vitamins}

So far as ascorbic acid and vitamin D are concerned, the problems of measurement are, of course, different. There is a dinitrophenylhydrazine method which is said to be very sensitive and specific for ascorbate, and Baker \& Frank (1968) suggest combining it with the use of dichlorophenolindophenol. Vitamin $\mathrm{D}$ can be measured colorimetically in foodstuffs, but it is necessary to separate vitamin A chromatographically, and biological methods of assay are frequently required.

\section{The clinical situation}

In continuation of the above, attention must first be paid to measurements in the human subject. So far as folate estimation in blood is concerned there would appear to be sufficient problems outlined in Table 3 but, in addition, there are the following: labile and stable factors can be measured microbiologically; vitamin $\mathrm{B}_{x 2}$ deficiency may alter the plasma folate concentration in either direction; red cell folate concentration exceeds that in plasma; a plasma factor releases folate from red cells in tests; red cell folate does not exchange in the body with plasma folate; ascorbic acid preserves folate released from red cells and is important in serum or plasma assays; vitamin $\mathrm{B}_{12}$ depletion lowers red cell folate.

In investigating suspected vitamin $\mathrm{C}$ deficiency, it can be said that ascorbic acid loading tests are of little value. The serum or plasma concentration can be estimated, but the best indication of tissue stores is the concentration in the white blood cellplatelet layer. In vitamin D deficiency, the serum alkaline phosphatase is raised, but the best index is probably a bone biopsy.

Most clinicians would agree that nutritional folate deficiency occurs in pregnancy and although it has been reported in alcoholics, this has not been our finding 
(Williams \& Girdwood, 1970). It occurs in old people to a variable extent in different parts of the country (Girdwood, 1969). Scurvy is seen in the elderly on occasion (Department of Health and Social Security, 1970), and osteomalacia is sometimes found in old people (Chalmers, Conacher, Gardner \& Scott, 1967). I do not share the view of Taylor (I 968 ) that vitamin-deficiency-states pose a serious problem in this country although Table 4 gives reasons why elderly people might suffer from deprivation. It may be that a fuller study of chronic alcoholics will show that there is a particular problem with them.

Table 4. Factors that may lead to vitamin deficiency in the elderly

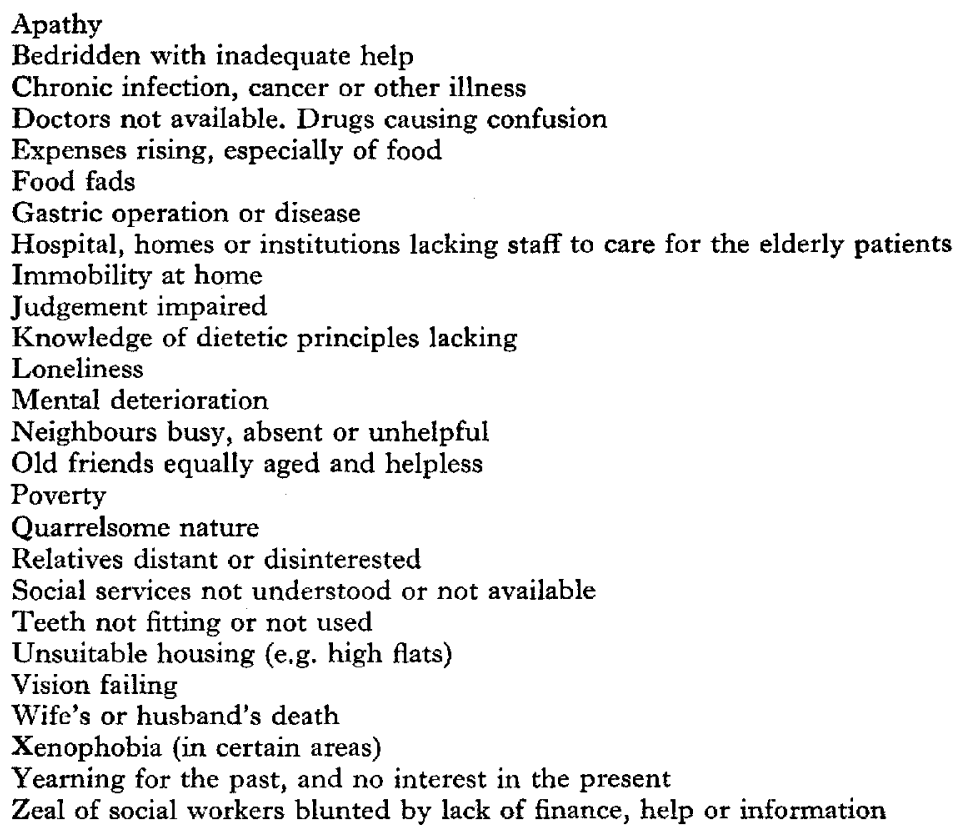

In other countries, matters may be entirely different and in Table 5 there is given a list of additional factors that may be involved. I should perhaps add here that not only vegans but some Hindu women in England have recently been reported to suffer from primary deficiency of vitamin $B_{12}$. (Stewart, Roberts \& Hoffbrand, 1970).

Table 5. Additional problems leading to vitamin deficiency as a global problem

\author{
Extreme poverty \\ Total ignorance of dietetic principles \\ Insufficient food production \\ Increasing population; large families \\ Multiplicity of diseases in an individual \\ Heavy work by malnourished \\ Lack of social services \\ Lack of compassion by authorities
}




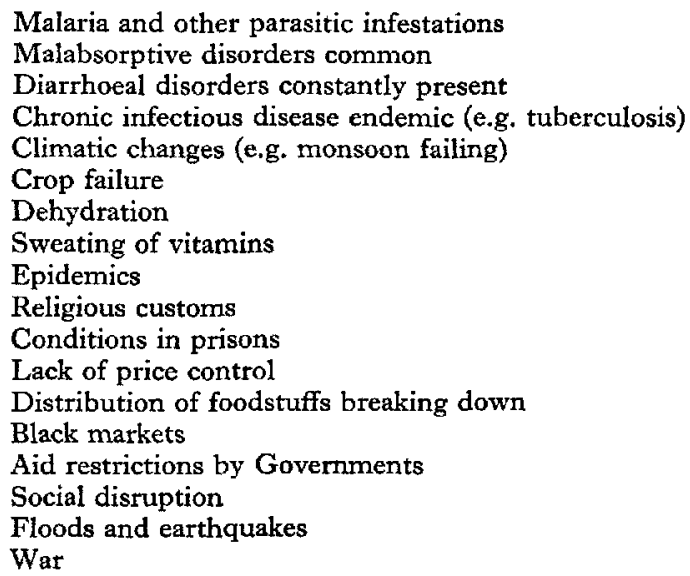

\section{Conclusions}

In summary, it is suggested that problems of primary vitamin deficiency in this country are found to a limited extent for three vitamins. Matters are entirely different in large areas of the globe and study in depth of all the factors would require an international conference or publication of a very large volume.

\section{REFERENCES}

Baker, H. \& Frank, O. (1968). Clinical Vitaminology-Methods and Interpretation Ist ed. New York: Interscience Publishers.

Bender, H. E. (1966). F. Fd Technol. r, 26r.

Chalmers, J., Conacher, W. D. H., Gardner, D. L. \& Scott, P. J. (1967). F. Bone ft Surg. 49B, 403.

Department of Health and Social Security (1970). Rep. publ. Hlth med. Subj., Lond. no, I23.

Girdwood, R. H. (1969). Scott. med, F. 14, 296.

Girdwood, R. H. (1970). Proceedings of a Seminar on Vitamins, Loughborough April, 1970. London: J. \& A. Churchill. (In the Press.)

Glew, G. (1970). Proceedings of a Seminar on Vitamins, Loughborough April, 197o. London: J. \& A. Churchill. (In the Press.)

Herbert, V. (1963). Am. F. clin. Nutr. 12, I7.

Ministry of Agriculture, Fisheries and Food (1969). Rep. natn. Fd Surv. Comm. 1967.

Stewart, J. S., Roberts, P. D. \& Hoffbrand, A. V. (1970). Lancet ii, 542.

Taylor, G. F. (1968). In Vitamins in the Elderly. Report of a Roche Symposium p. 51. [A. N. ExtonSmith and D. L. Scott, editors]. Bristol: John Wright and Sons Ltd.

Williams, I. R. \& Girdwood, R. H. (1970). Scott. med. F. r5, 285.

\section{Problems in formulating simple recommended allowances of amino acids for animals and man}

\section{By K.J. Carpenter, Department of Agricultural Science $\mathbb{O}^{\circ}$ Applied Biology, University of Cambridge}

There seem to be a special set of difficulties in recommending allowances of amino acids. With the vitamins and trace elements the overriding concern is to have an adequate safety factor. Most nutritionists probably believe that a large proportion 